Revista Brasileira de Agricultura Irrigada v.4, n.2, p.59-77, 2010

ISSN 1982-7679 (On-line)

Fortaleza, CE, INOVAGRI - http://www.inovagri.org.br/rbai

Protocolo 028.09 - 10/09/2009 Aprovado em 29/06/2010

\title{
DESEMPENHO DA IRRIGAÇÃO EM UM PROJETO HIDROAGRÍCOLA NO SUL DA ESPANHA: METODOLOGIA PARA ANÁLISE DA EFICIÊNCIA DE USO DA ÁGUA
}

\author{
Sílvio Carlos Ribeiro Vieira Lima ${ }^{1}$; José Antônio Frizzone ${ }^{2}$; Luciano Mateos ${ }^{3}$; \\ Maria Sierra Fernandez ${ }^{4}$ \\ ${ }^{1}$.Engenheiro Agrônomo, Professor do Instituto CENTEC, silviocarlos@yahoo.com.br. \\ ${ }^{2}$ Engenheiro Agrônomo, Prof. Titular, ESALQ/USP . \\ ${ }^{3}$ Engenheiro Agrônomo, Investigador Científico, IAS/CSIC - Córdoba -Espanha. \\ ${ }^{4}$ Engenheiro Agrônomo, Aluno Doctorado, UCO - Córdoba -Espanha.
}

\section{Resumo}

O Projeto de Irrigação Genil-Cabra (PIGC), Coletividade Santaella, está localizado na província de Córdoba-Espanha. Nesse Distrito avaliou-se a irrigação das campanhas de 2004/2005 e 2005/2006. Após a coleta dos dados, foram determinados indicadores da eficiência da irrigação na área. Para determinar a eficiência da irrigação, a pesquisa seguiu a metodologia utilizada por Mateos (2007). Como complementação a essa metodologia, foram introduzidas outras ferramentas, como DEM, SIG e entrevistas com os agricultores. No trabalho realizado por Fernandez et al. (2007), essa área estava dividida em 17 parcelas, denominadas recintos. Definiu-se uma nova delimitação da área, por meio de um DEM mais preciso e, após a nova delimitação e a realização da entrevista, identificou-se a necessidade de dividi-la em áreas de cadastro ou parcelas, com informações do produtor e do site oficial de cadastro. Dessa forma, a área passou a ter 33 parcelas, dando maior amplitude à pesquisa. A eficiência da irrigação do ano da campanha de 2005 foi 81,99\% e no de 2006, 90\%, o mesmo encontrado por Fernandez et al. (2007), o que se justifica pela irrigação deficitária realizada no PIGC. Visto que a irrigação foi deficitária, então certamente haverá uma maior produtividade da água no nível do recinto.

Palavras-chave: Eficiência da irrigação; Balanço de água; Irrigação deficitária 
Desempenho da irrigação em um projeto hidroagrícola no Sul da Espanha:

metodologia para análise da eficiência de uso da água

\section{ABSTRACT \\ PERFORMANCE ANALYSIS OF IRRIGATION IN A HYDRO- AGRICULTURAL PROJECT IN SOUTHERN SPAIN: METHODOLOGY FOR ANALYSIS OF EFFICIENCY USE OF WATER}

The Genil-Cabra irrigation scheme (GCIS), Coletividade Santaella, is located in Andalusia, southern Spain. It was evaluated the irrigation in 2004/2005 and 2005/2006 seasons. After collecting all data it was made a study to determine indicators to irrigation efficiency. To determine irrigation efficiency was followed the methodology used by Mateos (2007) complemented with the DEM, SIG and farmer interviews. In work made by Fernandez et al. (2007), this area was divided in 17 parcels called "recintos". It was defined a new area delimitation through a land digital model more precise, and after the new delimitation and the interviews, it was realized a necessity to divide them in areas or parcels, it identified by the farmers and by the official web records. In this way, the area became has to 33 parcels, and it gives bigger range to research. After the farmer interviews and compared the information with the orthophotos obtained from the web's records it was identified crops differentiated from Fernandez et al. (2007). The irrigation efficiency in the 2005 season was $81.99 \%$ and in 2006 was 90\%, same values encountered by Fernandez et al. (2007), that is due the deficit irrigation realized in the GCIS. Since the irrigation was with deficit, then likely will have bigger water productivity in the "recinto" level.

Keywords: Irrigation efficiency; Water balance; Deficit Irrigation

\section{INTRODUÇÃO}

$\mathrm{Na}$ Espanha, o Projeto de Irrigação Genil-Cabra (PIGC), Coletividade Santaella, está situado a 30 $\mathrm{km}$ do centro de Córdoba, onde o Instituto de Agricutlrua Sostenible/Consejo Superior de Investigaciones Científicas - IAS/CSIC tem uma grande atuação em pesquisa e difusão tecnológica. Nesse Distrito de Irrigação, existe uma forte atuação do setor público, auxiliando o setor privado para viabilizar pesquisas aplicadas, de cujos resultados os produtores são os maiores beneficiados.

A Comunidade Santaella começou a atuar na campanha de irrigação de 1990/1991 sobre uma área de 2.663 ha, ampliada para cerca de
6.900 ha em 1993/1994, e que se mantém constante até o presente, ocupando $45 \%$ da área do PIGC, onde trabalham $47 \%$ dos agricultores (IFAPA, 2005).

Um estudo hidrológico da área foi realizado por Lorite et al. (2005), com base na premissa de que a gestão na agricultura irrigada é uma condição indispensável para a conservação de água na agricultura. Os autores realizaram uma análise detalhada do desempenho da irrigação de cerca de 840 parcelas, no período de 1996 a 2000.

Fernandez et al. (2007) avaliaram o desempenho da irrigação e a contaminação difusa dessa área por agroquímicos, durante a campanha de 2005/2006, utilizando a metodologia de 
Duarte (2006), aplicada em Portugal. Os autores não obtiveram conclusões satisfatórias para a contaminação difusa, porém verificaram que a área utiliza irrigação deficitária com alto índice de eficiência.

Oportunidades para melhorar o desempenho dos sistemas de irrigação, sem dúvida, existem, mas são cada vez mais difíceis de conseguir, e raramente da magnitude sugerida em debates populares (PERRY et al., 2009). De acordo com estes autores, não há uma resposta simples para a pergunta "Qual método de irrigação é o melhor? ". O Irrigation and Drainage Division of the American Society of Civil Engineers (BURT et al., 1999) fornece uma referência que aborda essas complexidades. Tecnologia de irrigação é muitas vezes uma escolha ao nível de parcela, e é adequado considerar a perspectiva do agricultor com cuidado nas opções de entendimento e impactos. Agricultores investem em melhorias na tecnologia de irrigação por várias razões, incluindo: (a) aumento da renda; (b) aversão ao risco/segurança alimentar: os agricultores podem mudar de agricultura de sequeiro para irrigação para reduzir as incertezas associadas com os padrões de precipitação incerta; (c) conveniência: um agricultor pode não querer acordar no meio da noite para irrigar e fertirrigar, já que ele pode ser capaz de distribuir os fertilizantes com maior precisão e com maior economia através de sistemas de fertirrigação; (d) redução de custos: um agricultor pode economizar custos de bombeamento se as perdas de distribuição são reduzidas.

Playán e Mateos (2006) verificaram que, em grandes e antigos distritos de irrigação da Espanha, foram incentivadas técnicas de manejo para reduzir o consumo excessivo de água de determinadas culturas; como resultado, obtiveram uma considerável economia de água, com praticamente a mesma produtividade das culturas. Isso apenas com a orientação e a reeducação dos agricultores. Existe, na agricultura irrigada, muito mais do que apenas produção de alimento e de fibras. A irrigação é que mantém a água ligada ao meio rural, fixa a população em áreas desertas e contribui fundamentalmente para o valor social da água.

Muitas vezes, ao analisar a produção de culturas não é feita distinção entre transpiração (uso benéfico) e evaporação do solo e outras superfícies, consumo de água devido a dificuldades de ordem prática para estimar ou medi-los separadamente (usos não benéficos). Por isso, muitas vezes o consumo de água da cultura é relatado como evapotranspiração (ET) (PERRY et al., 2009). Segundo estes autores, a formulação de muitas das críticas populares da irrigação é simplista e falaciosa. A distinção entre usos consuntivos e não-consuntivos, benéficos e não-benéficos é identificar a medida na qual a água que não é consumida pode ser recuperada para $o$ uso produtivo em outros lugares. Essa terminologia é fundamental para a análise racional do desempenho dos sistemas de irrigação e das possibilidades de melhoria.

Indicadores de desempenho têm sido um componente da prática de irrigação, desde que o homem começou a controlar a água para aumentar a produção de alimentos. Os antigos egípcios monitoravam o nível de água do rio Nilo para saber qual área poderia ser irrigada, de modo a prevenir-se de enchentes e da falta de alimentos (BOS et al., 1994).

Segundo International Water Management Institute - IWMI (1999), indicadores de desempenho comparativos permitem observar o desempenho da agricultura irrigada e podem ser utilizados como ferramenta 


\section{Desempenho da irrigação em um projeto hidroagrícola no Sul da Espanha:}

\section{metodologia para análise da eficiência de uso da água}

para medir o desempenho relativo, ou para acompanhar o desempenho dos perímetros irrigados.

De acordo com Brito e Bos (1997), existe uma carência de metodologias de avaliação de perímetros, com enfoque global, ou seja, que possam fornecer uma idéia ampla sobre o desempenho dos perímetros, a partir de diferentes perspectivas. A falta de metodologias que permitam avaliar o desempenho de projetos, além de não possibilitar uma avaliação objetiva e sistemática, contribui para a manutenção deficitária dos perímetros, uma vez que não se dispõe de ferramentas para identificar onde estão os entraves e propor intervenções para corrigi-los.

$\mathrm{O}$ número de indicadores que se utilizará depende do nível de detalhes com o qual se necessita quantificar o desempenho, podendo um bom indicador ser usado de dois modos distintos. Por exemplo, quando ele informa como está o desempenho do projeto, em conjunto com outros indicadores, poderá auxiliar a identificação do curso correto de ações para melhorar esse desempenho. Dessa forma, o uso do mesmo indicador ao longo do tempo é importante, porque auxilia na identificação de tendências que se deverão rever, antes que medidas reparadoras se tornem muito caras ou complexas (BOS, 1997 citado por DIÓGENES, 2008). Segundo o autor, um verdadeiro indicador inclui um valor real e um valor planejado e permite a avaliação da divergência entre ambos, podendo, assim, avaliar-se se a divergência é aceitável ou não. Portanto é desejável expressar os indicadores na forma de uma razão entre a situação medida realmente e a situação pretendida ou planejada. Tais indicadores são utilizados para mostrar relações e tendências e serão úteis na identificação das situações que demandam estudos mais detalhados.

Mateos (2007) desenvolveu metodologia para avaliar os indicadores de desempenho da irrigação, em condições de déficit hídrico, a qual está sendo utilizada no Projeto de Irrigação Genil-Cabra, assim como é utilizada em diversas pesquisas na Espanha, principalmente em áreas irrigadas às margens do Mediterrâneo. A base da metodologia é a realização do balanço hídrico climatológico, para determinar a evapotranspiração das culturas em condições deficitárias de irrigação.

De posse de dados da irrigação pré-existentes de uma área irrigada, foram avaliadas a irrigação das campanhas de 2004/2005. Como complementação ao trabalho, foi utilizado um modelo digital de terreno, produzido pelo governo da Andaluzia, por meio do qual foi possível definir uma melhor delimitação da área que contribuiria com o estudo; um novo sistema de informação geográfica também foi elaborado e, para complementar a análise, foram realizadas entrevistas com os agricultores da área estudada, objetivando determinar os custos de produção na área, a adoção das novas tecnologias por parte da comunidade, a orientação do Sistema de Assessoramento ao Irrigante - SAR a produtividade e o consumo da água em cada parcela.

Após a coleta de todos os dados, foram realizados estudos dos dados para determinar indicadores, como a eficiência da irrigação, a produtividade da água e outros índices econômicos da irrigação. Esta pesquisa seguiu a metodologia utilizada por Mateos (2007) para avaliar a irrigação deficitária, que deverá futuramente ser alvo de aplicação em outras áreas irrigadas brasileiras. 


\section{MATERIAL E MÉTODOS}

A planície sul de Córdoba estende-se entre o vale do rio Guadalquivir e as Serras Subéticas, ao sul da província de Córdoba. Com uma extensão superficial total de 109.597 ha, que representa $8,75 \%$ do total provincial, ela se integra num conjunto de onze municípios, localizados entre Córdoba e Sevilha, que são Aguilar de la Frontera, Fernán Núñez, Montalbán de Córdoba, Montemayor, Montilla, Monturque, Moriles, La Rambla, Puente Genil, San Sebastián de los Ballesteros y Santaella (MATEOS, 2007).

O Projeto de Irrigação GenilCabra foi declarado de Interesse Nacional em 1974 e a superfície total que contempla é de 44.580 ha, dos quais estão prontos e transformados em área irrigada, somente 16.486 ha, com gestão dividida em duas coletividades, a de Puente Genil e a de Santaella. A comarca está cercada por numerosos afluentes do rio Guadalquivir. As principais bacias da zona são correspondentes aos rios Cabra, Genil e Guadajoz.

Os requerimentos de água dos cultivos existentes na área foram calculados para identificar como os irrigantes estavam aplicando a irrigação, se: com déficit, ou com excesso de água. Para tanto, foi utilizada uma planilha de cálculo baseada no procedimento descrito no manual $\mathrm{N}^{\circ} 56$ da FAO (ALLEN et al., 2006). Na planilha de cálculo foram obtidas as necessidades de irrigação das diferentes culturas existentes na área mediante o cálculo da evapotranspiração da cultura (ETc), a partir da equação de Penman Monteith, utilizando a evapotranspiração de referência (ETo), fornecida pela estação meteorológica do Instituto de Agricultura Sustentável, situada no PIGC. Para isto consideraram-se os efeitos produzidos pelos eventos de umedecimento do solo sobre o coeficiente da cultura $(\mathrm{Kc})$, dividindo-o em dois coeficientes, um para a transpiração da cultura, denominado coeficiente basal da cultura (Kcb), e outro para a evaporação do solo $(\mathrm{Ke})$. O coeficiente basal da cultura define-se como a relação entre a evapotranspiração da cultura e a evapotranspiração de referência, quando a superfície do solo se encontra seca, mas a transpiração mantém sua taxa potencial, ou seja, quando a transpiração não está limitada pela ausência de água (ALLEN et al., 2006).

Para calcular a evapotranspiração das distintas culturas seguiram-se os seguintes passos:

- Identificação das durações das distintas etapas de desenvolvimento dos cultivos e seleção dos valores de $\mathrm{Kcb}$ correspondentes, utilizando os valores proporcionados pelo manual $\mathrm{N}^{\circ} 56$ da FAO (ALLEN et al., 2006);

- Ajuste dos valores dos coeficientes $\mathrm{Kcb}$, segundo as condições climáticas de cada etapa;

- Construção da curva de coeficiente basal de cultivo para determinar os valores de $\mathrm{Kcb}$ em qualquer período durante a temporada de crescimento. Para isso somente se necessitam três valores de Kcb, correspondentes às etapas: inicial, de máximo desenvolvimento e final de cada cultivo;

- Determinação dos valores de Ke para a evaporação do solo. Esse valor será máximo quando a superfície do solo se encontra com umidade plena, depois da irrigação ou da chuva, e mínimo ou nulo quando não exista água na superfície do solo para ser evaporada;

- Cálculo da ETc.

Uma vez identificados todos os parâmetros necessários para o uso da 


\section{Desempenho da irrigação em um projeto hidroagrícola no Sul da Espanha:}

metodologia para análise da eficiência de uso da água

planilha de cálculo, procede-se a introdução dos valores (Figuras 1 a 8 ) para cada parcela e para cada cultura, levando-se em conta que, em uma mesma parcela, pode haver mais de uma cultura. Os dados meteorológicos, fornecidos pela estação do IAS/CSIC, situada no Projeto de Irrigação, foram introduzidos em uma tabela dentro da planilha de cálculo. Uma vez introduzidos todos os dados demandados para o cálculo das necessidades de irrigação, os resultados obtidos são registrados na tabela "Balanço de água e calendário" onde se inserem todas as fórmulas necessárias para o cálculo. Os resultados são apresentados na forma de gráficos e em uma tabela na qual aparece o resumo dos cálculos realizados (Figura 8).

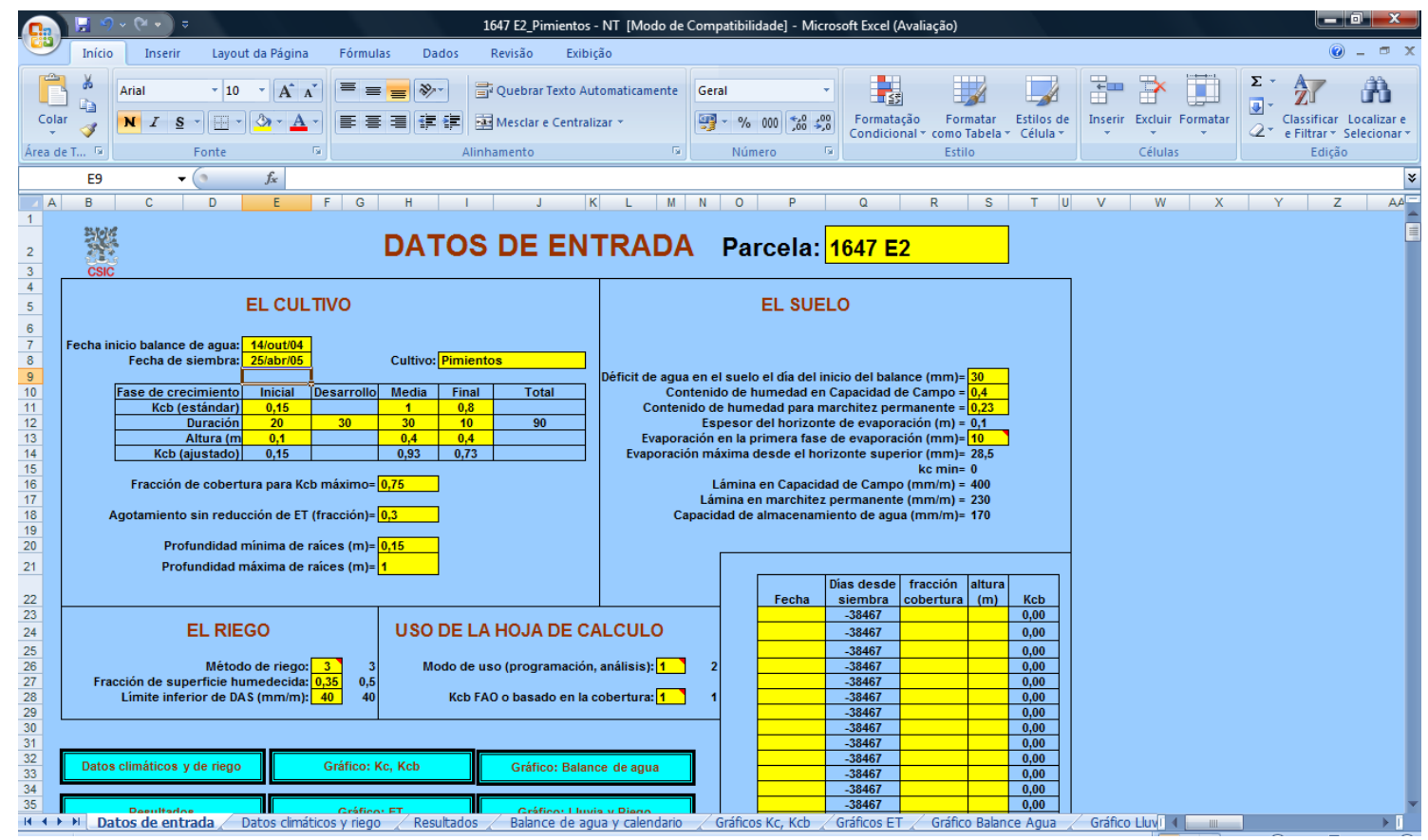

Figura 1 - Planilha de cálculo utilizada para cada cultivo proposta por Mateos (2007) 
Desempenho da irrigação em um projeto hidroagrícola no Sul da Espanha: metodologia para análise da eficiência de uso da água

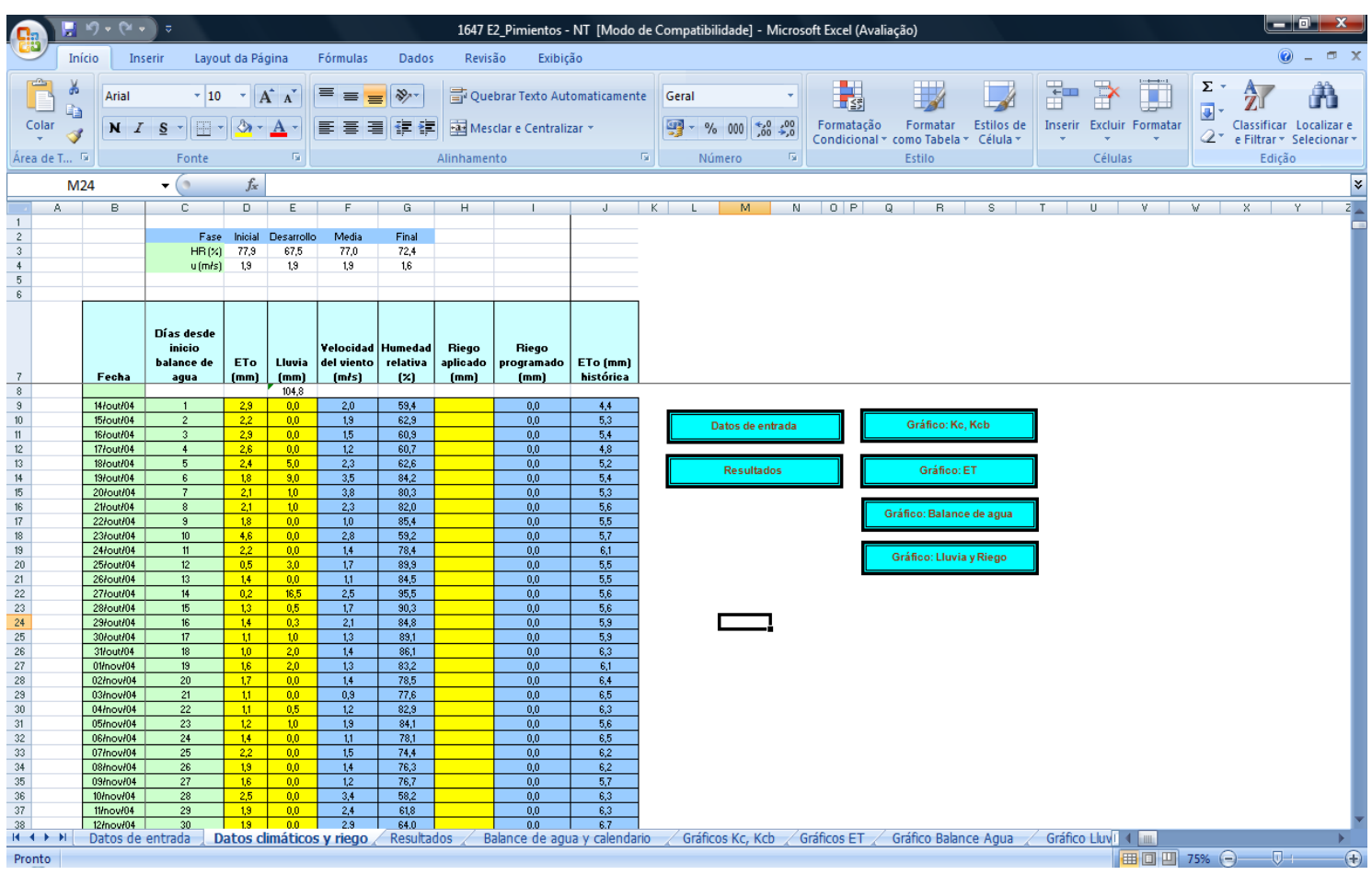

Figura 2 - Planilha de cálculo (dados climáticos e de irrigação) utilizada para cada cultivo, proposta por Mateos (2007)

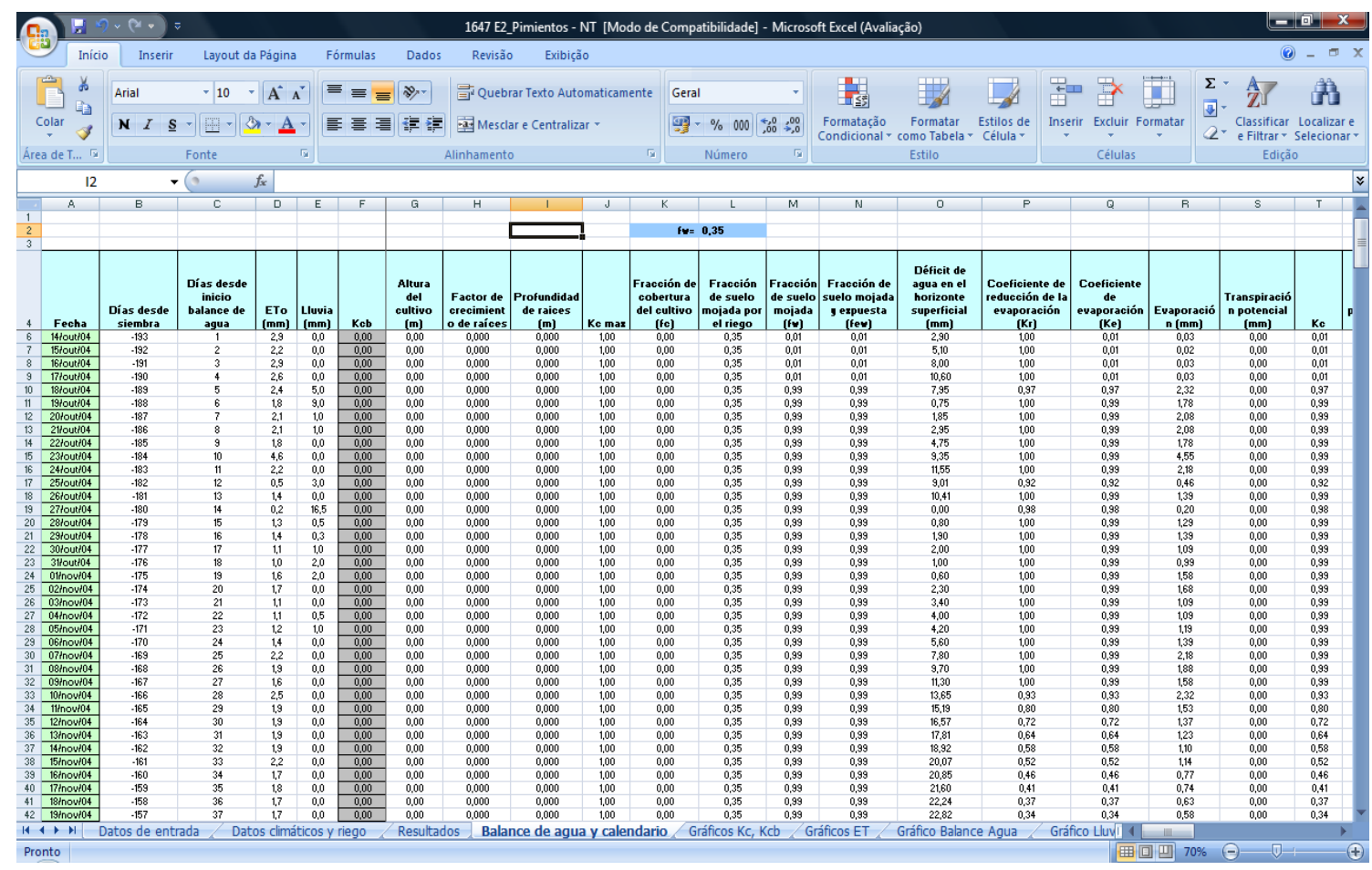

Figura 3 - Planilha de cálculo (Balanço de água e calendário) utilizada para cada cultivo proposta por Mateos (2007) 
Desempenho da irrigação em um projeto hidroagrícola no Sul da Espanha:

metodologia para análise da eficiência de uso da água

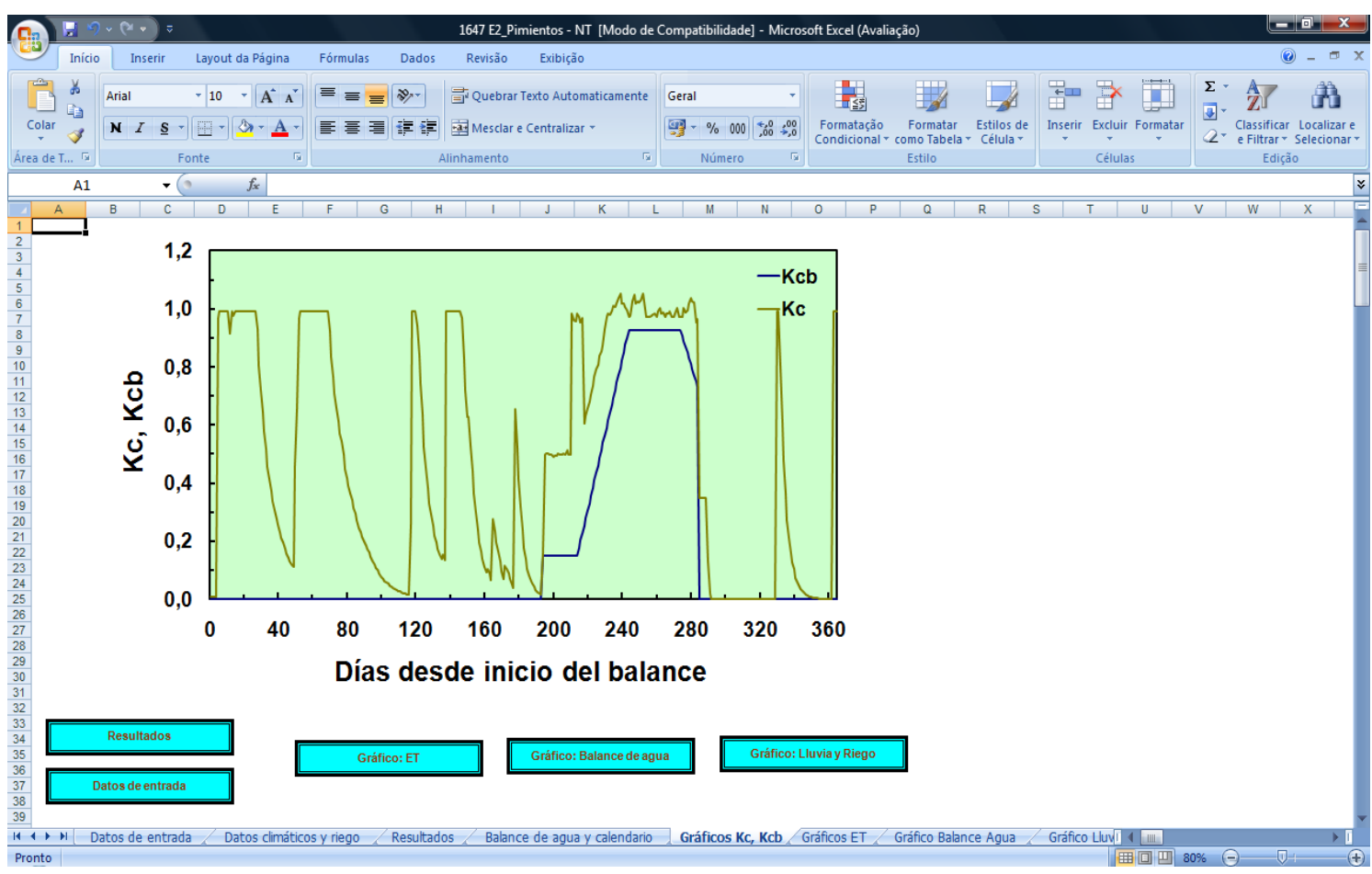

Figura 4 - Planilha de cálculo (Gráficos de Kc) utilizada para cada cultivo proposta por Mateos (2007)

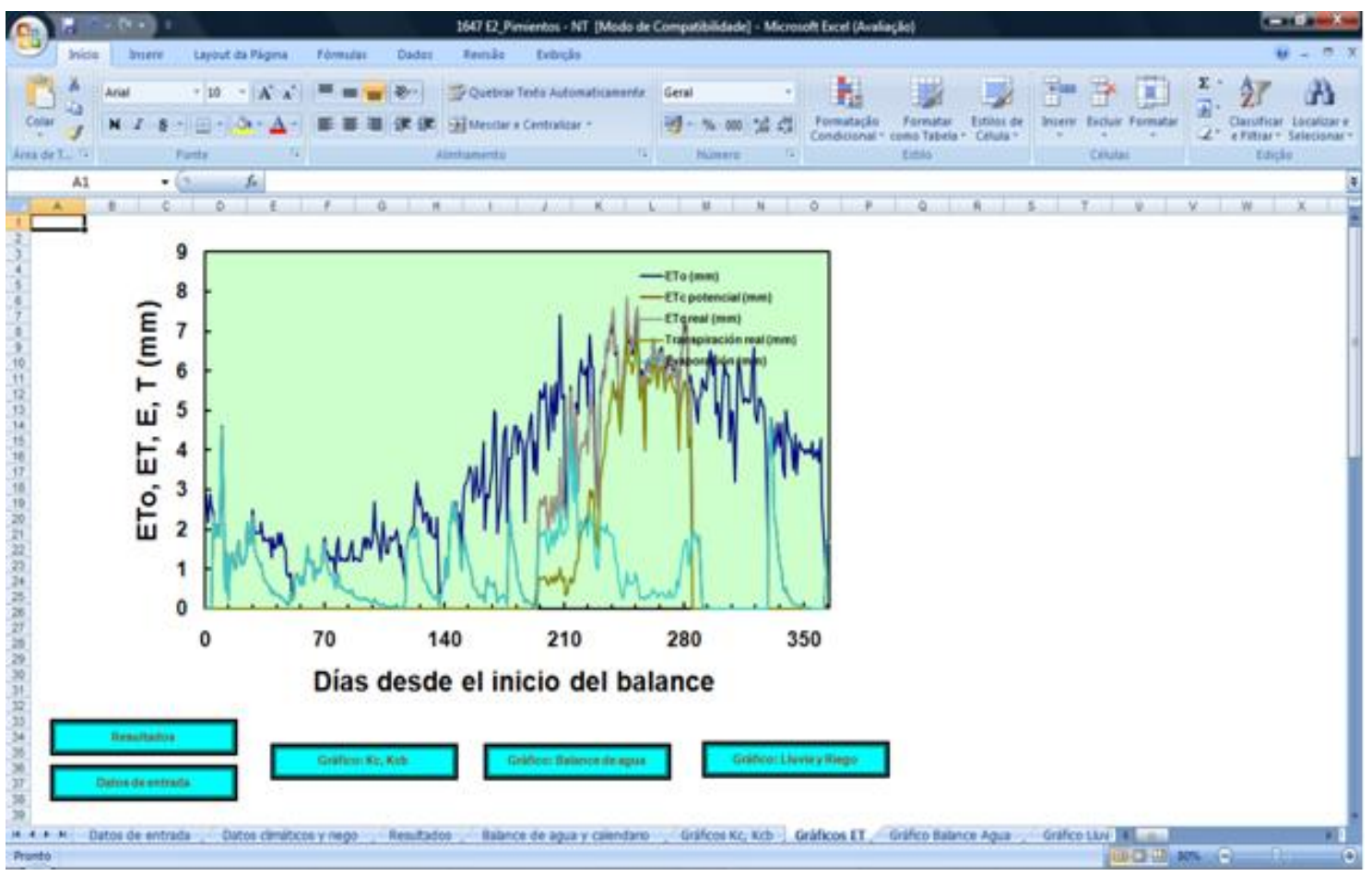

Figura 5 - Planilha de cálculo (Gráficos de ET) utilizada para cada cultivo proposta por Mateos (2007) 
Desempenho da irrigação em um projeto hidroagrícola no Sul da Espanha:

metodologia para análise da eficiência de uso da água

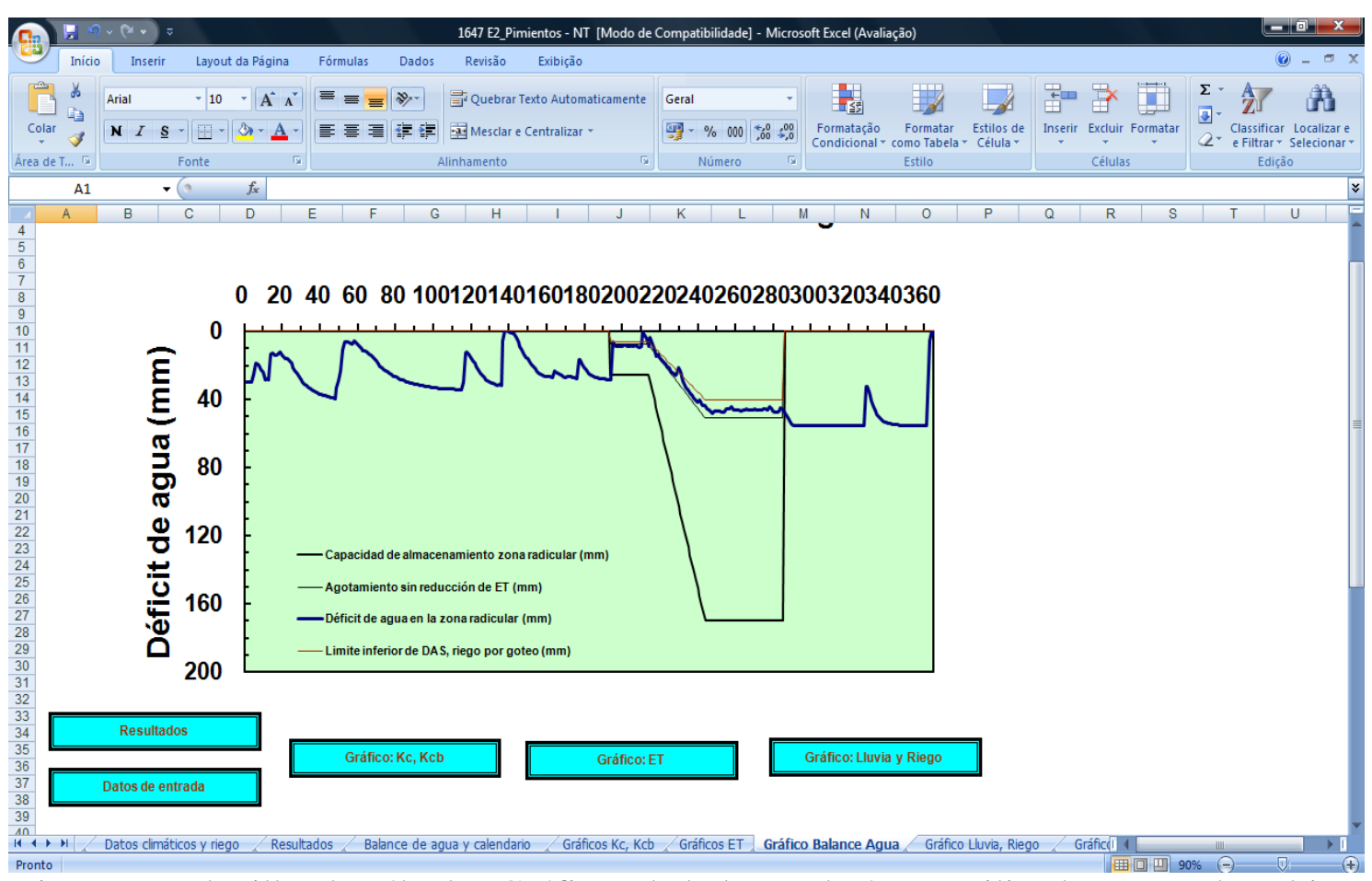

Figura 6 - Planilha de cálculo (Gráficos de balanço de água) utilizada para cada cultivo proposta por Mateos (2007)

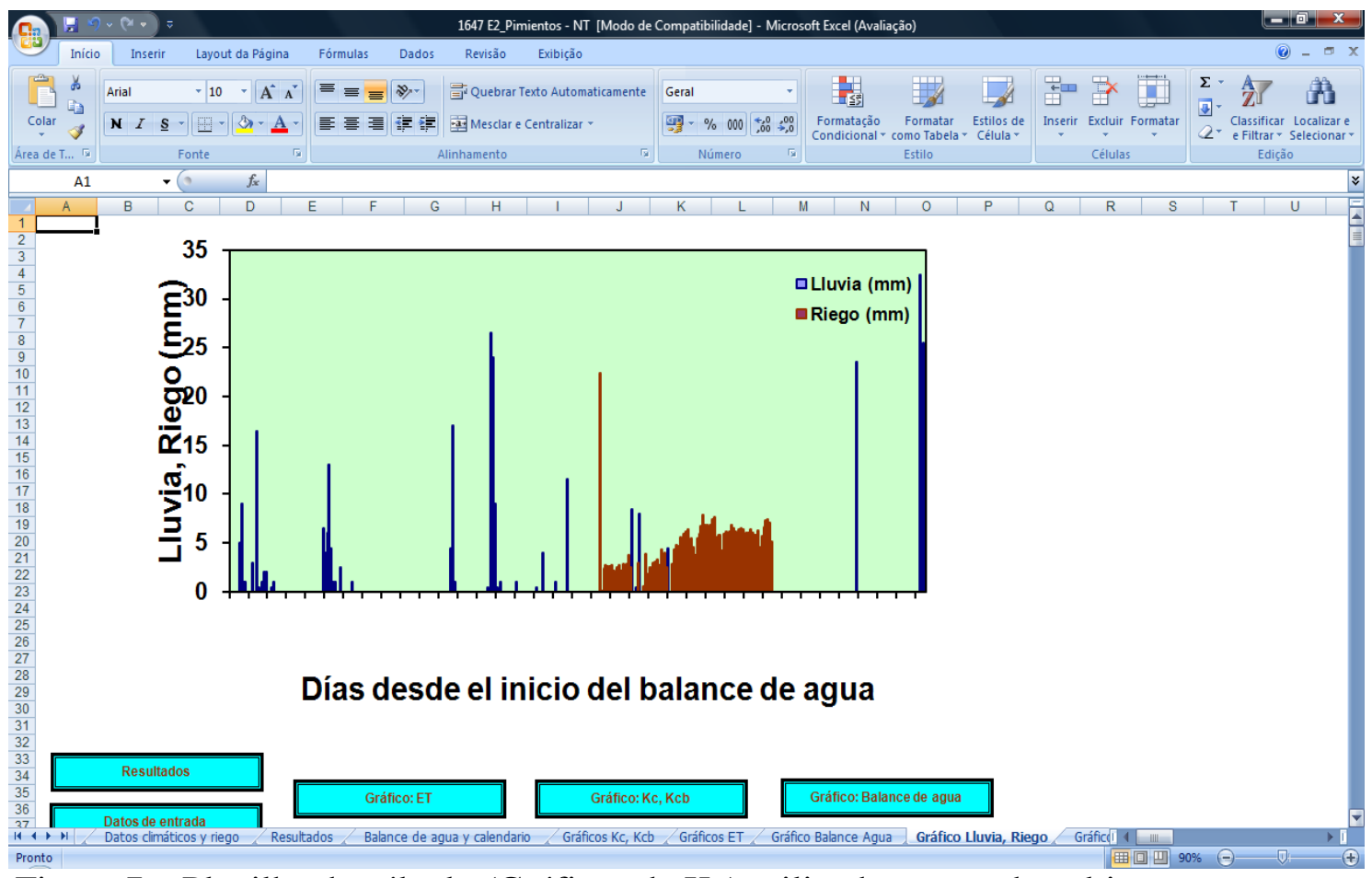

Figura 7 - Planilha de cálculo (Gráficos de Kc) utilizada para cada cultivo proposta por Mateos (2007) 


\section{Desempenho da irrigação em um projeto hidroagrícola no Sul da Espanha:}

\section{metodologia para análise da eficiência de uso da água}

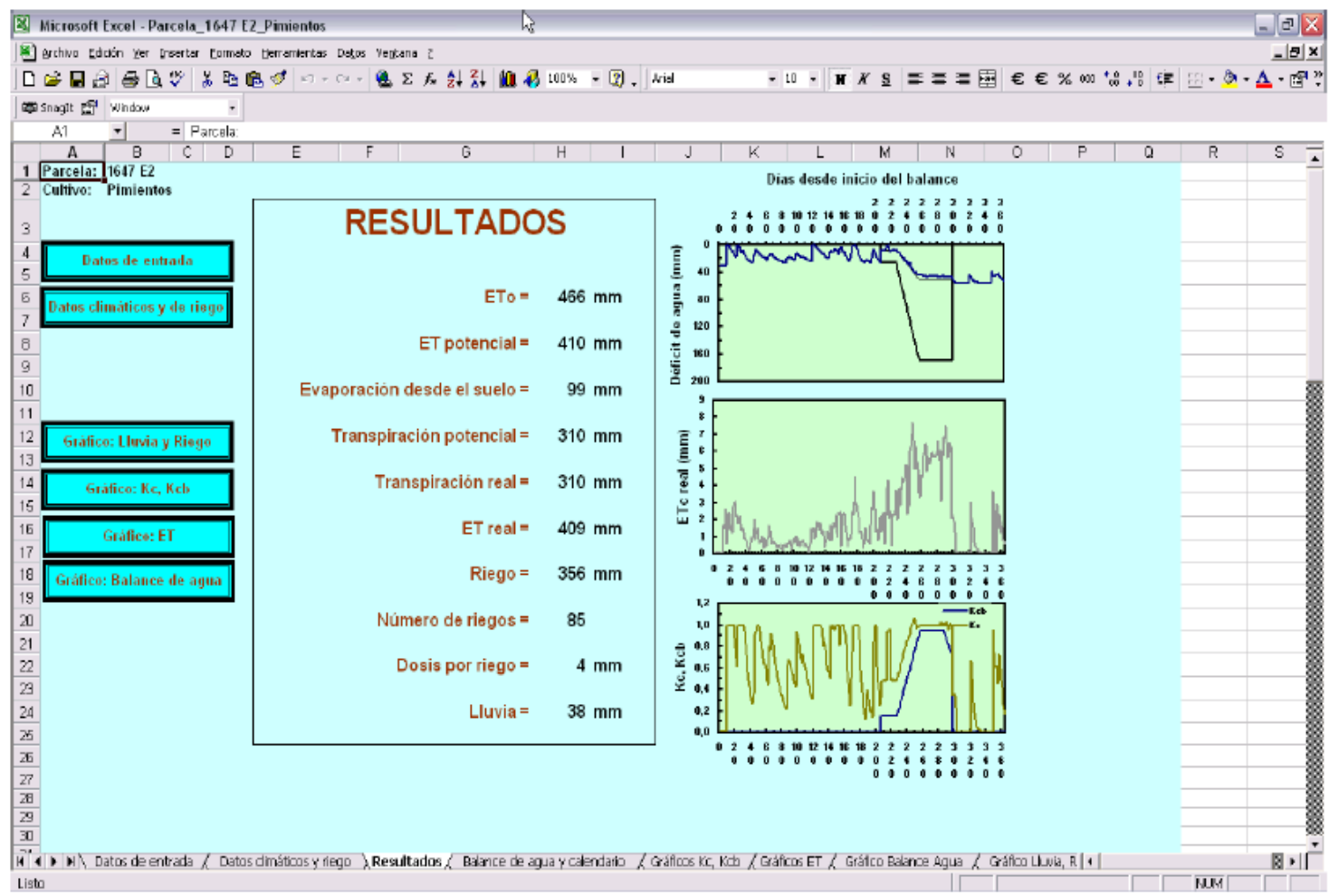

Figura 8 - Planilha de cálculo (Resultados) proposta por Mateos (2007)

Balanço de água na área e índices de irrigação.

Nesta parte estão explicados os índices que definem a irrigação realizada na área de estudo. Este estudo está baseado no balanço hídrico [equação (1)]:

$$
\mathrm{R}+\mathrm{ll}=\mathrm{ET}+\mathrm{Es}+\mathrm{P}+\Delta \mathrm{s}
$$

em que:

aplicado);

R: irrigação aplicada (riego

1l: precipitação (lluvia);

ET: evapotranspiração;

Es: escoamento superficial (escorrentía);

$\Delta \mathrm{S}$ : variação de armazenamento de água no solo;

P: percolação profunda.

Como exemplo, tendo em conta as condições meteorológicas no início e no final da campanha 2004/2005, pode- se considerar que o incremento de água no solo foi desprezível, mostrando-se a situação final do solo praticamente igual à do início da referida campanha. Devese observar que, nos solos deste Projeto de Irrigação existe uma camada adensada e relativamente de pouca profundidade, o que dificulta a percolação profunda, provindo os fluxos de retorno do escoamento superficial e sub-superficial.

Para saber o comportamento da irrigação na área, é necessário calcular uma série de índices, conforme o procedimento que segue. Primeiro, caluclou-se a evapotranspiração real ETreal [equação (2)]; para este solo, deve-se utilizar a equação do balanço de água, desprezando a percolação profunda e o incremento de água no solo:

$\mathrm{ET}_{\mathrm{REAL}}=\mathrm{R}+11-\mathrm{Es}$ 


\section{Desempenho da irrigação em um projeto hidroagrícola no Sul da Espanha:}

\section{metodologia para análise da eficiência de uso da água}

Uma vez calculada a evapotranspiração real e conhecida a evapotranspiração potencial $\left(\mathrm{ET}_{0}\right)$ pelo cálculo dos requerimentos dos cultivos, assumindo que nunca se incorre em déficit hídrico, passa-se a conhecer o coeficiente de déficit [equação (3)]:

Coeficiene de Déficit $=1-\frac{\mathrm{ET}_{\mathrm{REAL}}}{\mathrm{ET}_{0}}$

Os demais índices são o suprimento relativo de água (SAR) [equação (4)], que indica a relação entre volume total de água fornecida à bacia estudada (irrigação + chuva) e a evapotranspiração potencial, e o suprimento relativo de irrigação (SRR) [equação (5)], que indica a relação entre a água fornecida por irrigação aplicada pelos agricultores e o volume de água de irrigação requerida para máxima produção.

$$
\begin{aligned}
& \mathrm{SAR}=\frac{11+\mathrm{R}}{\mathrm{ET}_{\text {potencial }}} \\
& \mathrm{SRR}=\frac{\mathrm{R} \text { aplicada }}{\mathrm{R} \text { requerida }}
\end{aligned}
$$

A eficiência global de aplicação da irrigação, que se calcula pela equação (6), é a porcentagem de água de irrigação que fica no solo, para ser utilizada na evapotranspiração dos cultivos, em relação à água de irrigação total aplicada.

$$
\mathrm{Ea}=\frac{\mathrm{R}-\mathrm{E}_{\mathrm{s}}}{\mathrm{R}}
$$

A eficiência de aplicação é equivalente a um menos o rendimento hídrico, apresentado na equação (7), conceito utilizado em hidrologia, que se aplica à estação das chuvas e é definido como:

$\mathrm{RH}=\frac{\mathrm{Es}}{11}$

Esclarece-se que, nos termos $\mathrm{R}$ da equação (6) e 11 da equação (7) foram consideradas a pouca chuva e a pouca irrigação que, respectivamente, ocorrem na campanha de irrigação e na estação das chuvas.

Por último, calcula-se a eficiência da irrigação, que é a relação entre a evapotranspiração decorrente da água de irrigação e o volume total de água de irrigação aplicada.

$\mathrm{O}$ volume de evapotranspiração decorrente da irrigação obtém-se diminuindo-se, do volume de evapotranspiração real, o volume de precipitação durante esse período [equação (8)].

$\mathrm{ET}_{\text {águadeirrigação }}=\mathrm{ET}_{\mathrm{REAL}}-11$

A necessidade de refinar $o$ trabalho de sistema de informação geográfica realizado por Fernandez et al. (2007), foi de fundamental importância para o início da avaliação da área, tendo sido necessários os conhecimentos de geoprocessamento e sensoriamento remoto para organizar os dados. Nesta fase foram utilizados softwares modernos como o ArcGis 9.1 e softwares livres como o Kosmos 2.1.

A base de dados foi reformulada com informações dos agricultores, novas delimitações de área oriundos do novo DEM e os dados do balanço de água no solo. Após a alimentação dos dados no SIG, foi feito o geoprocessamento e gerados os mapas, utilizando as ferramentas dos softwares utilizados. 


\section{Desempenho da irrigação em um projeto hidroagrícola no Sul da Espanha:}

\section{metodologia para análise da eficiência de uso da água}

$\mathrm{Na}$ Figura 9 são mostrados os cultivos presentes na área, no ano de 2005, enquanto, na Figura 10, no ano de 2006. Nota-se que a área de cadastro difere sempre da área de recinto (Figura $11)$.
A razão é que a denominação recinto está relacionada à tomada de água da parcela, que pode até mesmo ter proprietários diferentes e quase sempre cultivos distintos em um mesmo recinto.

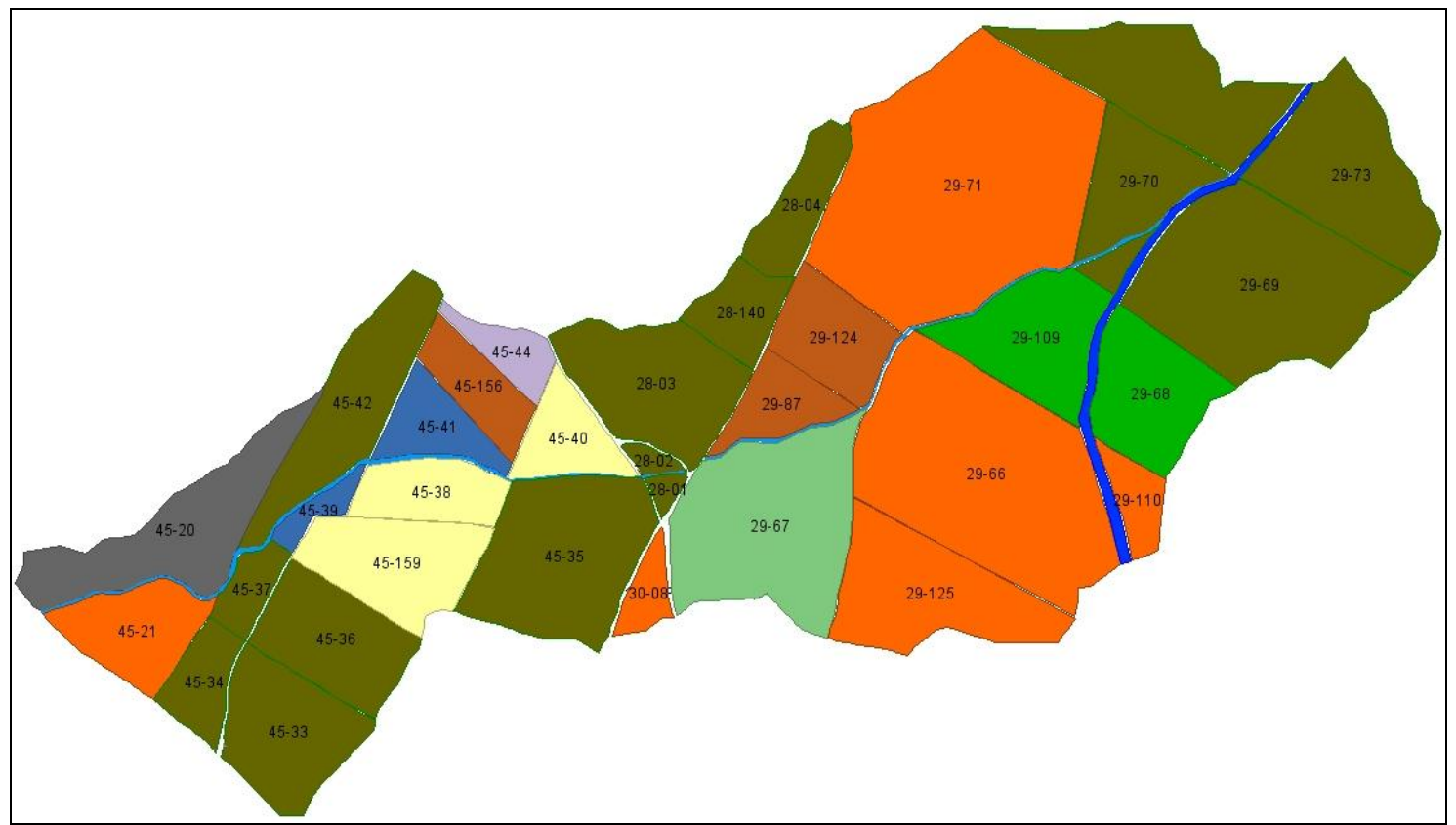

Figura 9 - Nova área com delimitação por Cadastros

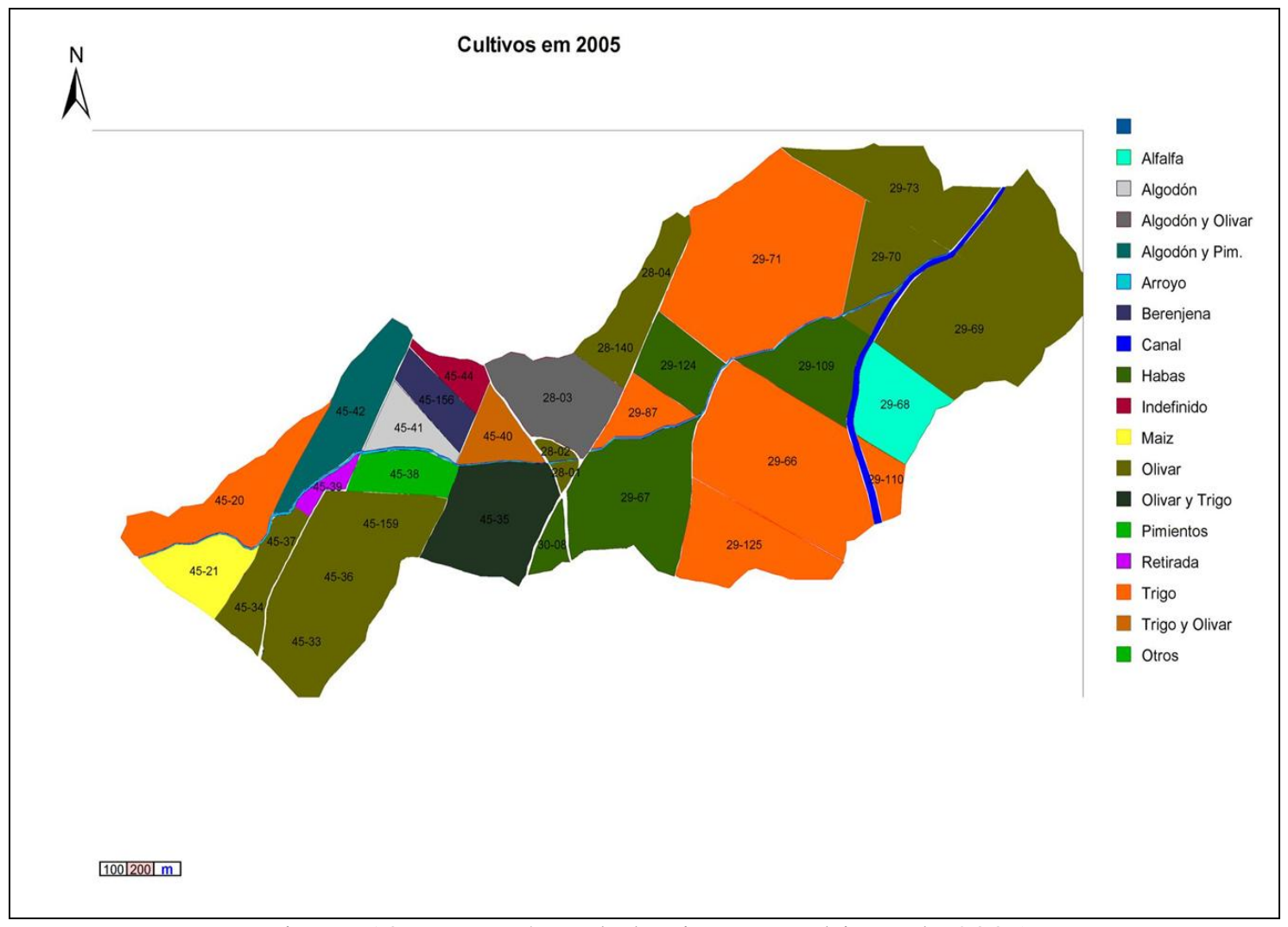

Figura 10 - Nova área da bacia com cultivos de 2005 
Desempenho da irrigação em um projeto hidroagrícola no Sul da Espanha:

metodologia para análise da eficiência de uso da água

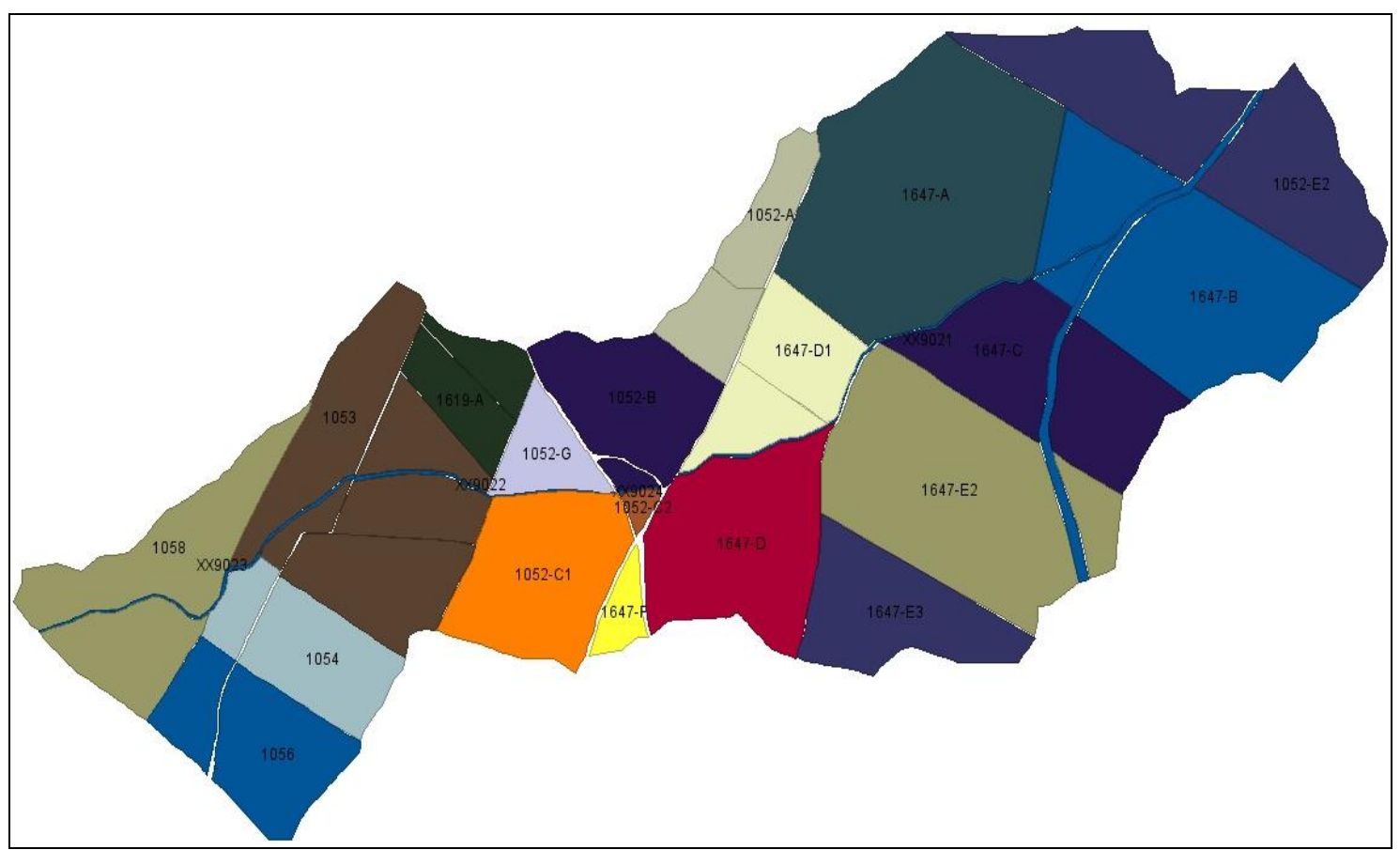

Figura 11 - Nova área por delimitação de Recintos

\section{Desempenho da irrigação}

Para analisar o desempenho da irrigação na área estudada utilizaram-se os dados de balanço de água e os índices de irrigação. $\mathrm{Na}$ Tabela 3 observa-se o monitoramento do consumo de água pelos hidrômetros. Como cada contador era referente a um recinto com duas ou mais áreas de cadastro, como discutido anteriormente, foi necessário relacionar o percentual de área em relação ao volume consumido na área total. Para análise do consumo, somente foram contabilizados os dados da campanha de 2005/2006. Portanto, tomaram-se como referência os mesmos valores para a campanha de 2004/2005. $\mathrm{Na}$ área de cadastro 29-73, cultivada com oliva, não houve monitoramento do volume aplicado. Constatou-se que o volume aplicado foi de $1.709 .739 \mathrm{~m}^{3}$. Dividindo este valor por 313,5 ha, ou seja, o volume pela área, obteve-se uma lâmina aplicada durante o ano de 545, $37 \mathrm{~mm}$.

\section{RESULTADOS E DISCUSSÃO}

Na Tabela 4 é mostrado um resumo dos dados obtidos neste estudo para a estação de chuva, a estação de irrigação, assim como para o total dos anos 2004/2005. Com os dados da Tabela 4 obtiveram-se os indicadores do desempenho da irrigação na área em estudo. Quando se comparam os 571 mm da lâmina aplicada com os 545, 37 $\mathrm{mm}$ do parágrafo anterior, a diferença é devida a alguns sensores serem utilizados em áreas fora da delimitação, bem como pequenas áreas dentro da bacia não estarem em monitoramento. Portanto, essa margem de aproximadamente $10 \%$ deve ser inserida no cálculo.

Como se observa, os índices de eficiência da irrigação foram elevados, embora o agricultor tenha mostrado tendência em utilizar mais água que o recomendado pelo SAR. Esse acréscimo de água utilizado pelo agricultor, embora de uso não-consuntivo (FRIZZONE, 2007, MATEOS, 2008), 


\section{Desempenho da irrigação em um projeto hidroagrícola no Sul da Espanha:}

\section{metodologia para análise da eficiência de uso da água}

neste caso, pode ser considerado intuitivamente pelo agricultor, como um uso benéfico, utilizado para lixiviação de sais, já que os solos são rasos e factíveis de salinização pela irrigação deficitária.

Um resumo de todos os dados está apresentado na Tabela 5. A evapotranspiração de referência foi obtida com os dados da estação meteorológica, instalada na área do estudo, e os valores diários, coletados pelo IAS/CSIC. Na Figura 12, apresenta-se a evapotranspiração dos períodos 2004-2005 e 2006-2007.

Na Figura 12 são mostrados os dados obtidos, neste estudo, para o período de um ano, de outubro de 2004 a setembro de 2005. Para melhor compreender os resultados apresenta-se a Figura 13, onde se observa a evolução dos parâmetros que definem o desempenho da irrigação na área em estudo, durante a estação de irrigação no período 2004/2005. Nela se percebe que a lâmina de irrigação aplicada é $81 \%$ da lâmina requerida, como indica a Tabela 5. Também quando é somada a precipitação durante este período, a lâmina total aplicada sobre a área é inferior à lâmina requerida que compensaria a demanda dos cultivos, o que confirma os resultados de outras pesquisas realizadas para a área de estudo, situada no PIGC, destacando-se a prática de irrigação deficitária, conforme se relata nos trabalhos de
Lorite et al. (2004b); Mateos (2007); Fernandez et al. (2007); Lorite et al. (2007); Santos et al. (2007); Garcia-Vila et al. (2008).

A aplicação de irrigação deficitária fez com que a eficiência da irrigação seja muito elevada na área estudada, principalmente na estação chuvosa, demonstrando o bom uso dos recursos hídricos. $\mathrm{Na}$ irrigação deficitária, o objetivo é maximizar a produção por unidade de volume de água aplicada (eficiência de uso da água = eficiência produtiva, atualmente denominada produtividade da água). Com esse objetivo, visa-se a aumentar a eficiência de uso da água e economizála pelo aumento da eficiência de aplicação (eficiência técnica), redução das perdas e redução da eficiência de armazenagem (PHENE, 1989), pressupondo-se que a disponibilidade de água constitui limitação à produção agrícola e que o manejo da irrigação deve priorizar a minimização das perdas de água. Sendo a lâmina de irrigação menor que a evapotranspiração da cultura no período, o grau de adequação será reduzido, as produtividades serão menores, mas, como resultado, reduz-se o escoamento, aumenta-se a eficiência de aplicação e há redução nos custos operacionais da irrigação e redução da lixiviação de produtos químicos. Isto é citado também no trabalho de Fernandez et al. (2007). 
Desempenho da irrigação em um projeto hidroagrícola no Sul da Espanha:

metodologia para análise da eficiência de uso da água

Tabela 3 - Resumo dos cálculos para definir o consumo de água no recinto

\begin{tabular}{|c|c|c|c|c|c|c|}
\hline Cadastro & $\begin{array}{l}\text { Área de } \\
\text { Recinto }\end{array}$ & Área cultivada & $\begin{array}{c}\text { Sensor de } \\
\text { água }\end{array}$ & $\begin{array}{l}\text { Percentual em } \\
\text { relação a toma } \\
\text { de água }\end{array}$ & $\begin{array}{c}\text { Consumo } \\
\text { identificado } \\
\text { sensor } \\
\text { (recinto) } \\
\end{array}$ & $\begin{array}{c}\text { Consumo } \\
\mathrm{x} \\
\text { percentual } \\
\left(\mathrm{m}^{3}\right)\end{array}$ \\
\hline $45-21$ & 62720 & 62720 & 72612 & 0,39 & 37796 & 14725 \\
\hline $45-20$ & 98264 & 77354 & 72612 & 0,61 & 37796 & 23071 \\
\hline $45-37$ & 23778 & 23778 & 66560 & 0,19 & 21597 & 4133 \\
\hline $45-36$ & 100468 & 100468 & 66560 & 0,81 & 21597 & 17464 \\
\hline $45-34$ & 24053 & 24053 & 67248 & 0,20 & 31015 & 6334 \\
\hline $45-33$ & 93724 & 93724 & 67248 & 0,80 & 31015 & 24681 \\
\hline $45-159$ & 101072 & 101072 & 65716 & 0,25 & 87704 & 21857 \\
\hline $45-39$ & 15045 & 15045 & 65716 & 0,04 & 87704 & 3254 \\
\hline $45-38$ & 48846 & 48846 & 65716 & 0,12 & 87704 & 10563 \\
\hline $45-41$ & 98300 & 98300 & 65716 & 0,24 & 87704 & 21258 \\
\hline \multirow{2}{*}{$45-42$} & 142300 & 105564 & 65716 & 0,14 & 87704 & 11894 \\
\hline & & & & 0,14 & 87704 & 11894 \\
\hline $45-156$ & 31100 & 31100 & 65916 & 0,49 & 3580 & 1771 \\
\hline $45-44$ & 31785 & 27974 & 65916 & 0,51 & 3580 & 1809 \\
\hline \multirow{2}{*}{$45-40$} & 47077 & 47077 & 76824 & 0,85 & 15988 & 13585 \\
\hline & & & & 0,15 & 15988 & 2377 \\
\hline \multirow{2}{*}{$45-35$} & 303232 & 70550 & 75968 & 0,80 & 36361 & 28922 \\
\hline & 77992 & 77992 & & 0,20 & 36361 & 7439 \\
\hline $30-08$ & 112076 & 19846 & 72584 & 1 & 21 & 21 \\
\hline 28-01 & 4968 & 4968 & 73616 & 1 & 1463 & 1463 \\
\hline $28-02$ & 5246 & 5246 & 77748 & 0,04 & 1205 & 47 \\
\hline \multirow{2}{*}{$28-03$} & 129100 & 114089 & 77748 & 0,82 & 1205 & 993 \\
\hline & & 18135 & 77749 & 0,14 & 1205 & 165 \\
\hline $28-140$ & 113741 & 39694 & 77870 & 0,49 & 16884 & 8263 \\
\hline $28-04$ & 118675 & 47353 & 77870 & 0,51 & 16884 & 8621 \\
\hline $29-67$ & 249660 & 178934 & 70284 & 0,56 & 44077 & 24633 \\
\hline $29-87$ & 52433 & 52433 & 70284 & 0,12 & 44077 & 5173 \\
\hline $29-124$ & 58537 & 58537 & 70284 & 0,13 & 44077 & 5776 \\
\hline 29-109 & 86104 & 86104 & 80788 & 0,33 & 1205 & 394 \\
\hline $29-68$ & 177100 & 87302 & 80788 & 0,67 & 1205 & 811 \\
\hline $29-66$ & 287950 & 287950 & 69760 & 0,39 & 142042 & 55736 \\
\hline $29-110$ & 67774 & 25543 & 69760 & 0,09 & 142042 & 13119 \\
\hline $29-125$ & 378106 & 56523 & 17312 & 1,00 & 95562 & 95562 \\
\hline $29-73$ & 631836 & 258350 & 0 & 0 & 0 & 0 \\
\hline $29-69$ & 257447 & 215068 & 80224 & 0,85 & 128205 & 108527 \\
\hline $29-70$ & 46681 & 46681 & 80224 & 0,15 & 128205 & 19678 \\
\hline $29-71$ & 386517 & 370760 & 79174 & 1 & 81277 & 81277 \\
\hline TOTAL & 4463707 & 2979133 & & & 1709739 & \\
\hline
\end{tabular}


Desempenho da irrigação em um projeto hidroagrícola no Sul da Espanha: metodologia para análise da eficiência de uso da água

Tabela 4 - Dados necessários para o cálculo do desempenho da irrigação em 2004/2005

TOTAL $\left(\mathbf{d m}^{3}\right)$

TOTAL (mm)

\begin{tabular}{|c|c|c|c|c|c|c|}
\hline & $\begin{array}{c}\text { Período } \\
\text { das } \\
\text { Chuvas }\end{array}$ & $\begin{array}{l}\text { Período } \\
\text { da } \\
\text { irrigação }\end{array}$ & Total & $\begin{array}{c}\text { Período } \\
\text { das } \\
\text { chuvas }\end{array}$ & $\begin{array}{c}\text { Período } \\
\text { da } \\
\text { irrigação }\end{array}$ & Total \\
\hline $\begin{array}{c}\text { Escoamento } \\
\text { superficial }\end{array}$ & 250 & 246 & 496 & 79 & 78 & 157 \\
\hline Precipitação & 612 & 364 & 976 & 194 & 115 & 309 \\
\hline Lâmina aplicada & 438 & 1366 & 1804 & 139 & 432 & 571 \\
\hline LL + Irrigação & 1049 & 1730 & 2779 & 332 & 548 & 880 \\
\hline ET potencial & 1475 & 1712 & 3187 & 467 & 542 & 1009 \\
\hline Lâmina requerida & 585 & 1641 & 2226 & 185 & 519 & 704 \\
\hline
\end{tabular}

Tabela 5 - Indicadores de desempenho da irrigação na área estudada - período 2004/2005

\begin{tabular}{|c|c|c|c|}
\hline & $\begin{array}{c}\text { Período das } \\
\text { chuvas }\end{array}$ & $\begin{array}{l}\text { Período da } \\
\text { irrigação }\end{array}$ & Total da campanha \\
\hline ET real $(\mathbf{m m})$ & 253,40 & 469,77 & 723,17 \\
\hline $\begin{array}{l}\text { Coeficiente de } \\
\text { Déficit }\end{array}$ & $45,81 \%$ & $13,30 \%$ & $28,29 \%$ \\
\hline SAR & $71,1 \%$ & $101,6 \%$ & $87,21 \%$ \\
\hline SRR & $75 \%$ & $83,00 \%$ & $81 \%$ \\
\hline ER & & $81,99 \%$ & \\
\hline
\end{tabular}

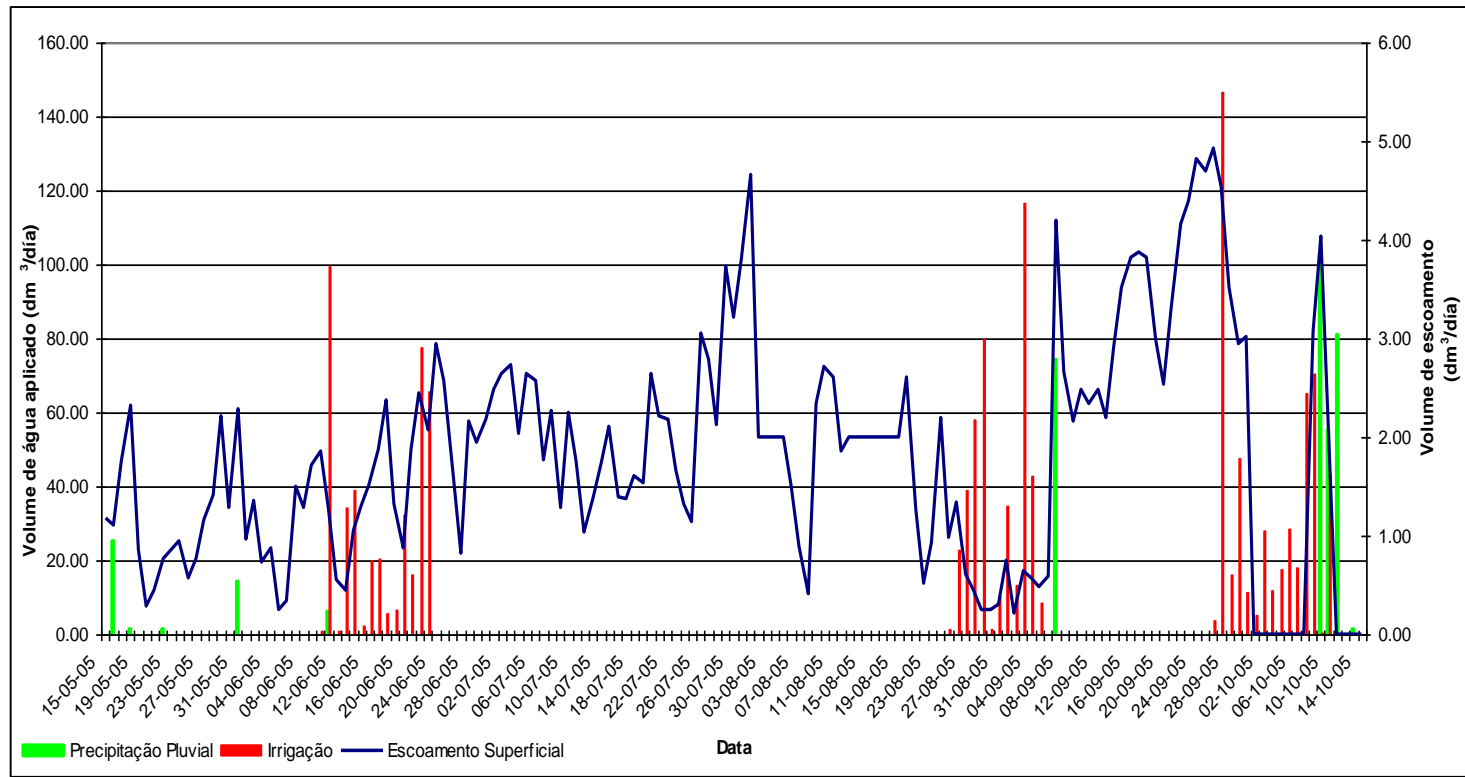

Figura 12 - Evolução da precipitação, da irrigação e do escoamento superficial durante a campanha da irrigação em 2005 


\section{Desempenho da irrigação em um projeto hidroagrícola no Sul da Espanha:}

metodologia para análise da eficiência de uso da água

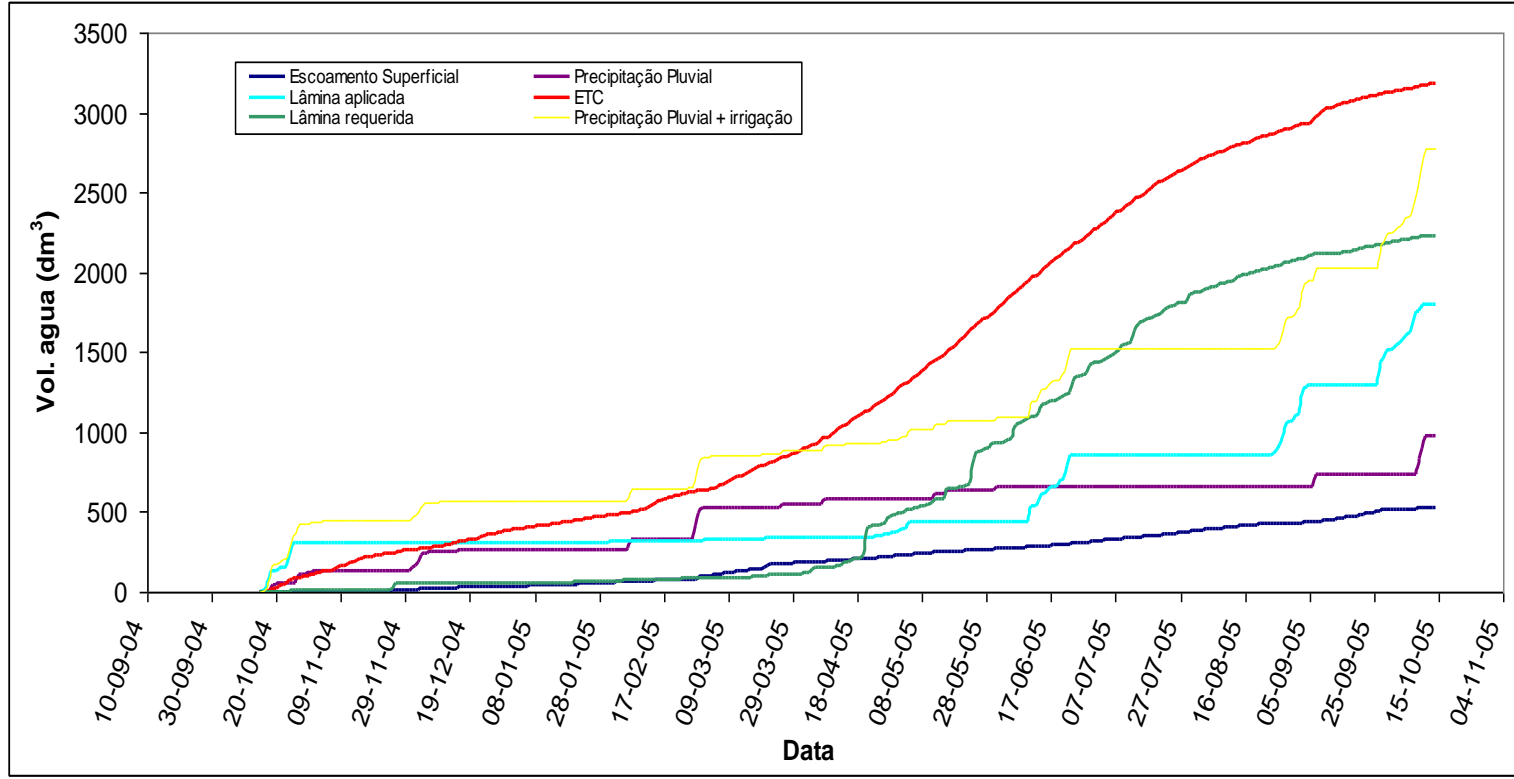

Figura 13 - Evolução dos parâmetros acumulados que definem o comportamento da área de estudo durante um ano de acompanhamento 2004/2005

\section{CONCLUSÕES}

Tendo como base, os resultados analisados, pode-se concluir que a eficiência do uso da água na área estudada foi alta, principalmente por que se trata de irrigação deficitária.

Em se tratando de avaliação, conclui-se que somente o uso de ferramentas independentes como o SIG, as entrevistas e o monitoramento da irrigação podem não produzir um impacto positivo na avaliação. Durante esta pesquisa, foram encontradas falhas em todas as metodologias, quando utilizadas em separado, corrigindo-se o erro somente quando utilizadas conjuntamente. Isso remete à conclusão de que, para uma área irrigada ser corretamente avaliada, necessita-se de um monitoramento correto da entrada e da saída de água, de visitas em campo, de entrevistas individuais com os agricultores e da utilização dessas informações para alimentar um sistema de informação geográfica, que deve ter o auxílio de sistemas de cadastros governamentais confiáveis, permitindo a correta confecção de mapas.

\section{REFERÊNCIAS}

ALLEN, R.G.; PEREIRA, L.S.; RAES, D.; SMITH, M. Crop evapotranspiration: guidelines for computing crop water requirements. Rome: FAO, 1998. 297 p. (FAO. Irrigation and Drainage Paper, 56).

BOS, M.G. Performance indicators for irrigation and drainage. Irrigation and Drainage Systems, Dordrecht, v. 11, p. 119-137, 1997.

BOS, M.G.; MURRAY-RUST, D.H.; MERREY, D.J.; JOHNSON, H.G.; SNELLEN, W.B. Methodologies for assessing performance of irrigation and drainage management. . Irrigation and Drainage Systems, Dordrecht, v. 7, p. 231-261, 1994.

BRITO, R.A.L.; BOS, M.G. Irrigation performance assessment in Brazil. Inception/Implementation: report. Sete Lagoas: EMBRAPA, 1997. $28 \mathrm{p}$. 
Desempenho da irrigação em um projeto hidroagrícola no Sul da Espanha:

metodologia para análise da eficiência de uso da água

BURT, C.M.; CLEMMENS, A.J.; BLIESNER, R.D.; MERRIAM, J.; HARDY, L.A. Selection of irrigation methods for agriculture. On-Farm Irrigation Committee. New York: ASCE, Water Resources Division, 1999. $129 \mathrm{p}$.

BURT, C.M.; CLEMMENS, A.J.; STRELKOFF, T.S.; SOLOMON, K.H.; BLIESNER, R.D.; HARDY, L.A.; HOWELL, T.A.; EISENHAUER, D.E. Irrigation performance measures: efficiency and uniformity. Journal of Irrigation and Drainage Engineering, New York, v. 123, n. 6, p. 423-442, 1997.

\section{DIÓGENES,}

F.C.A.

Indicadores de desempenho para $\mathrm{O}$ perímetro de brumado na perspectiva de sua autogestão. 2008. 60 p. Dissertação (Mestrado em Irrigação e Drenagem) - Universidade Federal do Ceará, Fortaleza, 2008.

DUARTE,

A.F.C.

Contaminación difusa originada por la actividad agrícola de riego, a escala de cuenca hidrográfica. 2006. 219 p. Tesis (Doctoral) - Escuela Técnica Superior de Ingenieros Agrónomos y de Montes, Universidad de Córdoba, Córdoba, 2006.

FERNÁNDEZ, $\quad$ M. S. S. F.; ASCENSIÓN, M.A.C.; MATEOS, L.; FERERES E. Comportamiento del riego a la escala de una pequeña cuenca In: MATEOS, L. Metodologías e instrumentos para a planificación y la gestión sostenible en condiciones de escassez de agua. Córdoba: CSIC, 2007. p. 31-50.

FRIZZONE, J.A. Planejamento da irrigação com uso de técnicas de otimização. Revista Brasileira de Agricultura Irrigada, Fortaleza, v. 1, n. 1, p. 24-49, dez. 2007.
INSTITUTO ANDALUZ DE INVESTIGACIÓN Y FORMACIÓN AGRARIA, $\quad$ PESQUERA, ALIMENTARIA Y DE LA PRODUCCIÓN ECOLÓGICA, Unidad de apoyo técnico al regadío andaluz. Córdoba: IFAPA, 2005. 10 p. (IFAPA Boletín Trimestral de Información, 1).

\section{INTERNATIONAL WATER MANAGEMENT INSTITUTE.} Comparative indicators for irrigation system performance. Sri Lanka: IWMI, 1999. 34 p.

LORITE, I.J.; MATEOS, L.; FERERES, E. Evaluating irrigation performance in a Mediterranean environment. I. Model and general assessment of an irrigation scheme. Irrigation Science, Amsterdam, v. 23, p. 77-84, 2004a.

Evaluating irrigation performance in a Mediterranean environment. II. Variability among crops and farmers. Irrigation Science, Amsterdam, v. 23, p. 85-92, 2004b.

Impact of spatial and temporal aggregation of imput parameters on the assessment of irrigation scheme performance. Journal of Hydrology, Amsterdam, v. 300, p. 286-299, 2005.

LORITE, I.J.; CARMONA, M.A.G.; MATEOS, L. Sistema de información geográfica de la zona regable genil-cabra, colectividad santaella In: MATEOS, L. Metodologías e instrumentos para a planificación y la gestión sostenible en condiciones de escassez de agua. Córdoba: CSIC, 2007. p. 63-68.

LORITE, I.J.; SANTOS, C.; CARMONA, S. Empleo de satélites y modelos de simulación para la 
Desempenho da irrigação em um projeto hidroagrícola no Sul da Espanha:

metodologia para análise da eficiência de uso da água

programación de riegos em GenilCabra. Agroboletín. Córdoba, n. 52, p. 3, jul. 2008.

LORITE, I.J.; MATEOS, L.; ORGAZ, F.; FERERES, E. Assessing deficit irrigation strategies at the level of an irrigation district. Agricultural Water Management, Amsterdam, v. 91 p. 51-60, 2007.

MATEOS, L. Metodología "mipais" para el riego en condiciones de escasez de agua In:

Metodologías e instrumentos para a planificación y la gestión sostenible en condiciones de escassez de agua. Córdoba: IAS/CSIC, 2007. cap. 4, p. 25-30.

Identifying a new paradigm for assessing irrigation system performance Irrigation Science, Amsterdam, v. 27, p. 25-34, 2008.

PERRY, C.; STEDUTO, P.; ALLEN, R.G.; BURT, C.M. Increasing productivity in irrigated agriculture: Agronomic constraints and hydrological realities. Agricultural Water Management, Amsterdam, v. 96, p.1517-1524, 2009.

PHENE, C.J. Techniques for computerized irrigation management. Computer and Eletronics in Agriculture, New York, v. 3, n. 3, p. 189-208, 1989.

PLAYÁN, E.; MATEOS, L. Modernization and optimization of irrigation systems to increase water productivity Agricultural Water Management, Amsterdam, v. 80, p. 100-116, 2006.

SANTOS, C.; LORITE, I.J.; TASUMI, M.; ALLEN, R.G.; FERERES, E. Integrating satellitebased evapotranspiration with simulation models for irrigation management at the scheme level. Irrigation Science, Amsterdam, v. 26, p. 277-288, 2008. 